\title{
A natural completely exhaust of the silted stones in Gallbladder managed with Chinese herbal medicine
}

\author{
Song feng Xin TCM${ }^{1}$, Ms Dan Jiang TCM²* \\ ${ }^{1}$ Principal and TCM consultant in Deguang TCM Hospital. \\ ${ }^{2}$ Hallam Institute of TCM, 439 Glossop Road Sheffield S10 2PR UK
}

*Corresponding Author: Dan Jiang, Hallam Institute of TCM, 439 Glossop Road Sheffield S10 2PR UK.

Received date: June 29, 2021; Accepted date: July 17, 2021; Published date: July 22, 2021

Citation: Song f Xin, D Jiang. (2021) A natural completely exhaust of the silted stones in Gallbladder managed with Chinese herbal medicine. Journal of Clinical and Laboratory Research. 3(2); DOI:10.31579/2768-0487/034

Copyright: (C2021 Dan Jiang. This is an open-access article distributed under the terms of the Creative Commons Attribution License, which permits unrestricted use, distribution, and reproduction in any medium, provided the original author and source are credited.

\begin{abstract}
:
Ms Xin suffered from gallbladder stores, Cholecystitis and Cholestasis in the bile duct with more or less attacks for four months of last sept to Dec 2019; Except a severe spasm on right costal and chest regions, he also manifested nausea, vomit and a bad jaundice who had been admitted to the accident \& emergency department in a few of hospitals in Beijing for rescuing and pain managements, she was offered an operation to remove gallbladder as an only way to completely release her suffers. But she accepted herbal medicine granules prescribed by Dr Xin. After three days of herbal taking, he was completely exhausted all of silted stones from his gallbladder and was healed at all. His state of the gallbladder have been proved by CT scans and blood tests. Conclusion: the herbal medicine is the safe and effective treating method to the gallbladder silted stones.

Key words: gallbladder silted stones; chinese herbal medicine
\end{abstract}

\section{Case report:}

Mr Z S Xin 32

Reoccurred spasm pain at right costal and chest regions for four months. On a night of last Sept, she was suddenly woken up by a spasm right costal and chest pain with nausea and vomit, then she was admitted into the accident \& emergency department of hospital in Beijing and was diagnosed a Multiple silted stones accumulated in the gallbladder, a Cholecystitis and Cholestasis in the bile duct with thicken gallbladder wall were confirmed by ultrasound and CT scans, relevant blood tests. He was eased off after he was infused by antibiotics and painkillers, and was offered an operation to remove his gallbladder later on.

Since there, she was reoccurred many times as these bad attacks from Sept to later Dec, he had been getting more and more severe symptoms, unbearable pain, even jaundice, she had lost more than $20 \mathrm{~kg}$ weight due to these frequent severe attacks during this 4 months, but she hesitated to be operated, after she visited four different hospitals in the central Beijing, she was given similar managements and offered operation as well.

Until he met Prof Xin - an experienced TCM consultant with PHD when she was attacked a severe gallbladder spasm pain with nausea and jaundice last Dec 2019. During this time, he got more than 700 on Bilirubin with urine in a brown colour, and abnormal results to the most of items on liver function. After carefully read her photos of CT scan, Dr Xin explained that the maximal stone in diameter was $0.9 \mathrm{~cm}$ although she had multiple stones in her gallbladder; because there was $1 \mathrm{~cm}$ in the bile duct, so it was possible to exhaust out for all of her gallbladder stones. Due to worry to operation, she decided to try the herbal treatment.

Diagnosis: Multiple Gallbladder stones Cholecystitis and Cholestasis with thicken gallbladder wall

Differentiation of syndrome with TCM: Qi stagnation and blood stasis with excessive damp and heat accumulated in the liver and gallbladder

Treating principle: to promote Qi’s movement and to release blood stasis for exhausting stones out

\section{Prescription on Chinese herbal medicine:}

Chaihu (Radix Bupleuri) 15,

Baishao (Radix Paeoniae Alba) 60,

Zhishi (Fructus Aurantii Immaturus) 10,

Zhizi (Fructus Gardeniae) 15,

Jinqiancao (Herba Glechomae Longitubae) 30,

Haijinsha (Spora Lygodii) 20,

Jineijin (Endothelium Corneum Gigeriae Galli) 20,

Sanqi (Radix Notoginseng ) 20, 
Hutaoren (Semen Juglandis) 20,

Zisuzi (Fructus Perillae) 10,

Baijiezi (Semen Sinapis Albae) 10,

Laifuzi (Semen Raphani) 10,

Shuihonghuazi (Fructus Polygoni Orientalis) 10,

Gancao (Radix Glycyrrhizae) 10,

Shengdahuang (Radix Et Rhizoma Rhei) 1

Above herbs were made to granular for taking melted with warm water, and be drunken herbal mixture in a small tea bag every an hour without any food restrictions during taking these herbs since $28^{\text {th }}$ Dec 2019.

\section{Result:}

After taking these herbs for three days, he sudden felt relaxed breathing, wide chest, pain and distension at the right costal, chest and upper abdominal region are completely disappeared in the $31^{\text {st }}$ Dec 2019, then, she recognized clear in her urination. She felt relaxation and comfortable in general. So she quickly went to local hospital for making all of relevant examination. Let all of doctors and herself surprised that all of silted stones in her gallbladder and bile duct had gone completely which were proved in CT Scan, Cholecystitis and Cholestasis had gone as well which were confirmed by Ultrasound and blood test. Due to very pleasant for this treating effect, the patient sent a silk banner for granting thanks to Prof Xin.

\section{Conclusion:}

From this case, we can proclaim that the Chinese herbal medicine, special a good designed herbal formula is the best effective way to exhausting the multiple silted stone. This treating method should be safer and cheaper for not only healing the severe gallbladder stones, but also maintaining the organ for patients, so it should be accepted by the most of patients.

\section{Reference:}

1. Chen Q, Zhang Y, Asakawa T and et al, (2019) Mechanisms Underlying the Prevention and Treatment of Cholelithiasis Using Traditional Chinese Medicine. Evidence-Based Complement and Alternative Medicine.2536452.

2. Li Y, Gao XX and, Qin XM. (2020) Advances in research of traditional Chinese medicine for promoting bile secretion and excretion China Journal of Chinese Materia Medica 45(6):1287-1296. (Chinese).

3. Ivanchenkova RA, Egorov AV, Leonovich AE and At'kova ER. (2012) Innovations in the diagnosis and treatment of cholelithiasis, Experimental and Clinical Gastroenterology. (4):66-73. (Russian).
This work is licensed under Creative Commons Attribution 4.0 License

To Submit Your Article Click Here: Submit Manuscript

DOI: $10.31579 / 2768-0487 / 034$
Ready to submit your research? Choose Auctores and benefit from:

* fast, convenient online submission

* rigorous peer review by experienced research in your field

* rapid publication on acceptance

* authors retain copyrights

* unique DOI for all articles

* immediate, unrestricted online access

At Auctores, research is always in progress.

Learn more auctoresonline.org/journals/clinical-pediatrics-and-motherhealth 